\title{
EFEKTIVITAS KERJA KARYAWAN DALAM PENGGUNAAN SISTEM ELEKTRONIK DOSIR PADA PT. ASABRI (PERSERO) PONTIANAK
}

\author{
Nurmalasari \\ Manajemen Informatika, AMIK BSI Pontianak \\ nurmalasari.nrr@bsi.ac.id
}

\begin{abstract}
The management of recordings of activities or sources of information that have a regular and well-planned use of both created and received files, to be easily recovered if necessary. This study aims to find out how effective employment in the use of Electronic Dossier system in PT.Asabri (Persero) Pontianak. This research was conducted at the Office PT.Asabri (Persero) Pontianak by taking the subject of research are employees or employees PT.Asabri Pontianak. The type of this research is descriptive qualitative, with data method used is observation (observation), interview, documentation and questionnaire. The results of the study that the effectiveness of employees in the use of electronic dossir system in PT. Asabri Pontianak is now running effectively. seen that the average percentage of respondents' answers relating to the effectiveness of employees in the use of electronic dossier system is 3.70 which means the respondents said the effectiveness of the use of electronic filing system in PT.Asabri Pontianak is very high / very good.
\end{abstract}

\section{Keywords: Archives, Electronic Dossier, and Work Effectiveness}

Abstrak - Pengelolaan catatan rekaman kegiatan atau sumber informasi yang memiliki nilai kegunaan dengan teratur dan terencana, baik itu arsip yang dibuat maupun diterima, agar mudah ditemukan kembali jika diperlukan. Penelitian ini bertujuan untuk mengetahui seberapa efektif pekerjaan dalam menggunakan sistem elektronik dosir di PT. Asabri (Persero) Pontianak. Penelitian ini dilakukan di Kantor PT. Asabri (Persero) Pontianak dengan mengambil subjek penelitian adalah karyawan yang bekerja pada PT. Asabri Pontianak. Jenis penelitian ini adalah deskriptif kualitatif, dengan metode data yang digunakan adalah observasi, wawancara, dokumentasi dan kuesioner. Hasil penelitian tersebut bahwa efektivitas kerja karyawan dalam penggunaan sistem elektronik dosir yang ada di PT. Asabri Pontianak saat ini sudah berjalan dengan efektif. terlihat bahwa presentase rata-rata jawaban responden yang berkaitan dengan efektivitas kerja karyawan dalam penggunaan sistem elektronik dosir adalah sebesar 3,70 yang berarti responden menyatakan efektivitas kerja penggunaan sistem kearsipan elektronik di PT.Asabri Pontianak tergolong sangat tinggi atau sangat baik.

Kata Kunci: Arsip, Elektronik Dosir, dan Efektivitas Kerja

\section{A. PENDAHULUAN}

Di era globalisasi saat ini yang semakin berkembang dibidang teknologi informasi yang semkain cepat dan mudah. Perkembangan teknologi informasi yang semakin pesat sangat membantu unit kerja baik diinstansi-instansi pemerintah maupun swasta. Dengan perkembangan dan kemajuan teknologi informasi pengaksesan terhadap data atau informasi yang tersedia dapat berlangsung dengan cepat efisien dan keakuratan informasi.

Pengelolaan arsip merupakan aspek penting dalam suatu organisasi, baik organisasi bisnis maupun pemerintahan. Bertambahnya volume pekerjaan suatu organisasi, menyebabkan bertambah pula jumlah arsip yang dihasilkan. Jumlah arsip yang semakin banyak dari waktu ke waktu, membutuhkan penanganan yang baik agar informasi yang terkandung di dalam arsip tersebut dapat ditemukan dengan cepat dan tepat.

Pengertian kearsipan adalah pengelolaan catatan rekaman kegiatan atau sumber informasi yang memiliki nilai kegunaan dengan teratur dan terencana baik itu arsip yang dibuat maupun diterima, agar mudah ditemukan kembali jika diperlukan. Sistem kearsipan yang diselenggarakan secara optimal akan memperlancar kegiatan dan tujuan lembaga, organisasi, badan maupun perseorangan.

Mengingat jumlah arsip yang semakin banyak dibuat dan diterima oleh lembaga, organisasi, badan maupun perseorangan maka diperlukan manajemen pengelolaan arsip yang lebih dikenal dengan sistem kearsipan melalui beberapa pekerjaan atau kegiatan untuk mengelola arsip yang ada.

Pengertian Arsip elektronik merupakan informasi yang terkandung dalam file dan media elektronik, yang dibuat, diterima, atau 
dikelola oleh organisasi maupun perorangan dan menyimpannya sebagai bukti kegiatan.

Pengelolaan arsip secara elektronik mempunyai banyak manfaat, terutama Menurut Peraturan Menteri Pertahanan Republik Indonesia Nomor 43 Tahun 2013 bahwa dalam rangka meningkatkan sistem manajemen kepegawaian yang berbasis kompetensi dan terwujudnya tertib administrasi, dibutuhkan ketersediaan dosir dan dosir elektronik yang berisi himpunan data/dokumen autentik pegawai. Dosir adalah kumpulan dari tulisan-tulisan dinas atau bahan-bahanlainnya yang dikeluarkan oleh pejabat berwenang sebagai bukti telah terjadinya suatu tindakan administrasi bagi perseorangan,menunjukkan perjalanan karier sejak pengangkatan sampai dengan purna tugas, yang perlu dipelihara dan disimpan dalam jangka waktu tertentu selama masih diperlukan. Dosir Elektronik adalah data/dokumen autentik perseorangan yang disimpan dan disajikan dalam bentuk visual atau cetak.

Sistem kearsipan elektronik dapat mempermudah kinerja bagi seorang karyawan, serta meningkatkan efisiensi kerja karyawan, dimana semua proses kerjanya dibantu dengan menggunakan media alat elektronik yang modern. Seiring dengan perkembangan teknologi informasi, pengelolaan arsip konvensional mulai disertai dengan sistem pengelolaan arsip secara elektronik. Sebagian besar organisasi bisnis maupun pemerintahan di era sekarang ini telah banyak menghasilkan dokumen dalam bentuk elektronik

PT. Asabri merupakan BUMN yang bergerak dibidang asuransi sosial dan pembayaran pensiunan khusus untuk Prajurit TNI, Anggota Polri, PNS Kementerian Pertahanan Republik Indonesia dan POLRI. Tenaga kerja di PT. ASABRI pun merupakan prajurit TNI dan POLRI yang masih aktif. Seiring berkembangnya teknologi informasi dan telekomunikasi penerapan aplikasi E-Dosir dilingkungan kerja PT. ASABRI dalam perekapan data atau himpunan data/dokumen autentik perseorangan yang menunjukkan kepersertaannya dalam asuransi terhitung sejak pengangkatan sampai dengan purna tugas sebagai prajurit TNI, anggota POLRI dan PNS Kementerian Pertahanan Republik Indonesia.

Sistem e-Dosir ini memberikan kemudahan dalam penginputan, pencarian data peserta asuransi, pengarsipan dokumen asuransi berupa digital hingga menghasilkan laporan akhir. Sehingga, pelayanan prima yang diberikan oleh PT ASABRI kepada peserta asuransi dapat meningkat

Dalam meningkatkan pelayanan prima saatnya memperbaiki pola pikir dan budaya kerja organisasi guna meningkatkan efektivitas kerja. Untuk meningkatkan efektivitas kerja karyawan dapat diawali dengan menciptakan sistem administrasi yang baik, karena administrasi merupakan bagian terluar dari suatu organisasi. Selain itu setiap unit organisasi baik organisasi pemerintah maupun swasta tentunya melaksanakan urusan yang berhubungan dengan administrasi dan setiap saat memerlukan informasi baik dalam surat atau dokumen yang dibuat maupun diterima. Informasi tersebut merupakan salah satu bahan dalam rangka pengambilan keputusan dan menunjang efektivitas kerja. Pengelolaan arsip yang baik tidak lepas dari berbagai faktor yang mendukung. Banyak faktor yang mempengaruhi agar kearsipan mempunyai citra yang positif, antara lain adalah kerapihan penyimpanan, kebersihan tempat penyimpanan, petugas yang terdidik dan terampil, kemudahan untuk menyimpan dan menemukan kembali arsip, terjaminnya keamanan arsip dan sebagainya (Sularso Mulyono dkk, 2011: 37). Berkenaan dengan hal tersebut, arsip sebagai pusat ingatan dan sumber informasi akan melancarkan kehidupan dan perkembangan organisasi.

\section{B. TINJAUAN PUSTAKA}

\section{Pengertian Arsip}

Menurut Sugiarto dan Wahyono (2005:3) membahas kearsipan tentunya tidak akan lepas dari istilah arsip. "Istilah arsip berasal dari bahasa Yunani, yaitu dari kata Arche, kemudian berubah menjadi Archea. Archea artinya dokumen/catatan mengenai permasalahan". Sedangkan Menurut The Liang Gie dalam bukunya Agus Sugiarto dan Teguh Wahyono (2005: 4) arsip adalah suatu kumpulan dokumen yang disimpan secara sistematis karena mempunyai suatu kegunaan agar setiap kali diperlukan dapat secara cepat ditemukan.

Arsip mempunyai peran penting dalam eksistensi organisasi-organisasi pemerintah dan swasta. Manfaat arsip bagi suatu organisasi antara lain yaitu informasi yang terkandung dalam arsip, dapat dijadikan dasar dalam pengambilan keputusan, alat bukti apabila terjadi masalah, alat pertanggungjawaban manajemen, dan bahan transparansi birokasi (Kuswantoro \& Saeroji, 2014).

Dari beberapa definisi arsip diatas dapat ditarik kesimpulan bahwa arsip merupakan sekumpulan berkas berisi informasi yang 
disimpan sebagai bahan pengingat dalam bentuk lembaran catatan maupun bentuk lain.

\section{Arisp Elektronik}

The Georgia Archives (2004) dalam Badri Munir Sukoco (2006:111) menyebutkan bahwa arsip atau dokumen elektronik dapat berasal dari berbagai bentuk, yaitu semua dokumen, kertas, surat, peta, buku (kecuali buku yang dikelola oleh perpustakaan), microfilm, magnetic tape, atau bahan lain tanpa menghiraukan bentuk fisik atau karakteristik, dibuat atau diterima menurut undangundang. Menurut (Kuswantoro \&Saeroji, 2014) arsip elektronik adalah sistem penyimpanan arsip berbasis komputer, jika dikembangkan melalui internet, maka dapat di onlinekan, sehingga dapat digunakan olehorganisasi atau lembaga yang besar.

Sistem diartikan sebagai mekanisme yang mengatur data dan informasi mulai dari pengumpulan, pemilihan, pengelolaan, penyimpanan, penemuan kembali, penyajian, pendistribusian, kepada para manajemen atau pengambilan keputusan (Sugiarto \& Wahyono, 2014).

Sedangkan Menurut Read \& Ginn (2011:313) "electronic record is a record stored on electronic storage media that can 5be readly accessed or changed". Maksud dari definisi di atas adalah bahwa arsip elektonik merupakan arsip yang disimpan dalam media penyimpanan elektronik yang dapat diakses atau diubah. Lebih lanjut Read \& Ginn (2011:313) menambahkan bahwa "electronic records may contain quantitative data, text, images, or sounds that originate as an electronic signal". Maksudnya adalah bahwa arsip elektronik dapat berisi data kuantitatif, teks, gambar, atau suara yang bersumber dari sinyal elektronik. Pengertian arsip elektronik lainnya menurut Haryadi (2009:67) dalah kumpulan data yang disimpan dalam bentuk data scanan yang dipindakan secara elektronik atau dilakukan dengan digital copy menggunakan resolusi tinggi, kemudian disimpan ke dalam hard drive atau optical disk. Sedarmayanti (2005:53) juga mengungkapkan bahwa arsip elektronik adalah suatu sistem kearsipan yang menggunakan sarana pengolahan data elektronik.

Sistem kearsipan elektronik pada dasarnya memiliki konsep yang sama dengan teknik kearsipan konvensional. Jika pada kearsipan konvensional memiliki cabinet yang secara fisik berfungsi untuk menyimpan dokumen-dokumen penting yang dimiliki perusahaan, maka sistem kearsipan berbasis komputer ini memiliki kabinet virtual yang di dalamnya berisi map virtual. Selanjutnya di dalam map virtual berisi lembaran-lembaran arsip yang telah di konversi ke dalam bentuk file gambar $\left({ }^{*}\right.$. bmp, jpg, dll) atau dokumen $\left({ }^{*}\right.$. doc, txt,dll).

\section{Manfaat dalam penggunaan Arsip Elektronik}

Kearsipan dalam suatu organisasi berfungsi sebagai penunjang kelancaran kegiatan operasional organisasi. Melalui kearsipan inilah informasi dan data yang otentik dan akurat dapat diperoleh dengan cepat dan mudah. Menurut Odegers (2005:371), beberapa keuntungan dari pengelolaan arsip secara elektronik antara lain:

a) Cepat ditemukan dan memungkinkan pemanfaatan arsip tanpa meninggalkan meja kerja;

b) Pengindeksan yang fleksibel dan mudah dimodifikasi;

c) Pencarian secara

d) full-text;

e) Kecil kemungkinan file akan hilang;

f) Menghemat tempat;

g) Mengurangi resiko kerusakan arsip karena disimpan secara digital;

h) Memudahkan berbagi (sharing) arsip;

i) Meningkatkan keamanan;

j) Mudah dalam recovery data

Terdapat beberapa manfaat penggunaan sistem pengelolaan dokumen secara elektronik yang diungkapkan Badri Munir Sukoco (2007: 112) dalam bukunya Manajemen Adminstrasi Perkantoran Modern sebagai berikut:

a) Cepat ditemukan dan memungkinkan pemanfaatan arsip atau dokumen tanpa meninggalkan meja kerja.

b) Pengindeksan yang fleksibel dan mudah dimodifikasi berdasarkan prosedur yang telah dikembangkan akan menghemat tenaga, waktu, dan biaya. Dibandingkan dengan mengubah sistem indeks kertas yang mengakibatkan berlaku hal sebaliknya.

c) Pencarian secara full-text, dengan mencari file berdasrakan kata kunci maupun nama file dan menemukannya dalam bentuk full text dokumen.

d) Kecil kemungkinan file hilang, hal ini disebabkan karena kita hanya dapat melihat dilayar monitor atau mengeprint-nya tanpa dapat mengubahnya. Kita dapat juga mencarinya berdasarkan kata atau nama file jika tanpa sengaja terpindahkan. Tentunya ada prosedur untuk memback-up file 
ke dalam media lain, misalnya CD atau external hard disk.

e) Menghemat tempat, dengan kemampuan 1 CD-RW berkapasitas $700 \mathrm{MB}$ akan mampu menyimpan dokumen dalam bentuk teks sebanyak \pm 700 lembar (1 lembar setara dengan $100 \mathrm{~KB}$ dalam format PDF) atau \pm 700 lembar foto (1 lembar setara dengan $1 \mathrm{MB}$ dalam format JPG).

f) Mengarsip secara digital, sehingga resiko rusaknya dokumen kertas atau buram karena usia dapat diminimalsir karena tersimpan secara digital. Juga resiko akan berpindahnya dokumen ke folder yang tidak semestinya atau bahkan hilang sekalipun akan aman karena disimpan secara digital.

g) Berbagi arsip secara mudah, karena berbagi dokumen dengan kolega maupun klien akan mudah dilakukan melalui LAN bahkan Internet.

h) Meningkatkan keamanan, Karena mekanisme kontrol secara jelas dicantumkan pada buku pedoman pengarsipan secara elektronis, maka orang yang tidak mempunyai otorisasi relatif sulit untuk mengaksesnya.

i) Mudah dalam melakukan recovery data, dengan memback-up data kedalam media penyimpanan yang compatible. Bandingkan dengan merecovery dokumen kertas yang telah sebagian terbakar atau terkena musibah banjir ataupun pencurian, pemback-upan akan sulit dilakukan lagi.

Arsip mempunyai fungsi yang sangat penting yaitu sebagai sumber informasi dan dokumentasi. Sebagai sumber informasi maka arsip akan dapat membantu mengingatkan petugas yang lupa mengenai sesuatu masalah. Sebagai sumber dokumentasi arsip dapat dipergunakan oleh pimpinan organisasi untuk membuat atau mengambil keputusan secara tepat mengenai suatu masalah yang dihadapi.

\section{Konsep Dasar Efektivitas}

Atmosoeprapto (2002 :139) menyatakan Efektivitas adalah melakukan hal yang benar, sedangkan efisiensi adalah melakukan hal secara benar, atau efektivitas adalah sejauh mana kita mencapai sasaran dan efisiensi adalah bagaimana kita mencampur segala sumber daya secara cermat. Menurut Stoner dalam Kurniawan (2005:106) menekankan pentingnya efektivitas organisasi dalam pencapaian tujuan-tujuan organisasi dan efektivitas adalah kunci dari kesuksesan suatu organisasi. Efektivitas dalam kegiatan organisasi dapat dirumuskan sebagai tingkat perwujudan sasaran yang menunjukkan sejauh mana sasaran telah dicapai. Sedangkan Sumaryadi (2005:105) berpendapat dalam bukunya bahwa organisasi dapat dikatakan efektif bila organisasi tersebut dapat sepenuhnya mencapai sasaran yang telah ditetapkan.

Efektivitas umumnya dipandang sebagai tingkat pencapaian tujuan operatif dan operasional dengan demikian jelaslah bahwa efektifitas merupakan suatu keadaan yang menunjukkan keberhasilan kerja yang diharapkan. Efektivitas kerja adalah penyelesaian pekerjaan tepat pada waktu yang telah ditentukan, artinya pelaksanaan suatu tugas ditandai baik atau tidak sangat tergantung pada penyelesaian tugas tersebut, bagaimana cara melaksanakannya, dan berapa biaya yang dikeluarkan untuk itu. Menurut Handoko, Efektivitas merupakan kemampuan untuk memilih tujuan yang tepat atau peralatan yang tepat untuk pencapaian tujuan yang ditetapkan.

Berdasarkan pendapat para ahli diatas, maka dapat disimpulkan bahwa konsep tingkat efektivitas kerja menunjuk pada tingkat sejauh mana pegawai melaksanakan kegiatan atau fungsi-fungsi sehingga tujuan yang telah ditetapkan dapat tercapai dengan menggunakan secara optimal alat-alat dan sumber-sumber yang ada, ketepatan waktu dalam melaksanakan tugas serta kemampuan untuk melaksanakan tugas tersebut yang dapat dilihat dari kualitas maupun kuantitas dan dapat bermanfaat bagi lingkungan kerjanya.

Menurut The Liang Gie (2000:29) Faktorfaktor yang mempengaruhi efektivitas kerja dalam organisasi :

a) Waktu : Ketepatan waktu dalam menyelesaikan suatu pekerjaan merupakan faktor utama. Semakin lama tugas yang dibebankan itu dikerjakan, maka semakin banyak tugas lain menyusul dan hal ini akan memperkecil tingkat efektivitas kerja karena memakan waktu yang tidak sedikit.

b) Tugas : Bawahan harus diberitahukan maksud dan pentingnya tugas-tugas yang didelegasikan kepada karyawan.

c) Produktivitas : Seorang karyawan mempunyai produktivitas kerja yang tinggi dalam bekerja tentunya akan dapat menghasilkan efektivitas kerja yang baik demikian pula sebaliknya.

d) Lingkungan kerja: Lingkungan tempat bekerja adalah menyangkut tata ruang, cahaya alam dan pengaruh suara yang 
mempengaruhi konsentrasi seorang pegawai sewaktu bekerja.

e) Perlengkapan dan Fasilitas : Perlengkapan fasilitas adalah suatu sarana dan peralatan yang disediakan dalam bekerja. Fasilitaas yang kurang lengkap akan mempengaruhi kelancaran pegawai dalam bekerja. Semakin baiknya kerja seseorang dalam mencapai tujuan atau hasil yang diharapkan.

Dalam mengukur efektivitas kerja suatu organisasi perlu adanya ukuran atau indikator pengukurannya. Indikator untuk mengukur efektivitas kerja menurut Richard dan M. Steers (1980:192 dalam Zuliyanti, 2005: 29) meliputi: kemampuan menyesuaikan diri, prestasi kerja, dan kepuasan kerja.

Jadi dapat disimpulkan efektivitas kerja adalah kemampuan untuk memilih tujuannya tepat atau peralatan - peralatan untuk pencapaian tujuan yang telah ditetapkan.

\section{METODE PENELITIAN}

Jenis penelitian yang digunakan dalam penelitian ini adalah penelitian deskriptif dengan pendekatan kualitatif. Penelitian deskriptif ini termasuk jenis penelitian deskriptif yang didalamnya menggunakan teknik wawancara, observasi, dokumentasi dan angket.

Dalam penelitian ini yang dideskripsikan adalah efektivitas kaerja karyawan dalam penggunaan Elektronik Dosir pada PT. Asabri Pontianak.

Responden dalam penelitian ini adalah seluruh pegawai atau karyawan pada PT.Asabri Pontianak sebanyak 9 orang. Dalam mengumpulkan data, peneliti menggunakan teknik observasi, dokumentasi, wawancara, dan angket. Angket yang digunakan peneliti yaitu membahas masalah efektivitas karyawan dalam penggunaan sistem elektronik dosir di PT. Asabri Pontianak dengan menggunakan pengukuran skala likert yang digunakan untuk mengukur efektivitas karyawan terhadap penggunaan sistem elektronik dosir dengan skor pengukuran sebagai berikut:

Tabel 1. Skor Penilaian Angket

\begin{tabular}{|c|c|}
\hline Pendapat & Skor \\
\hline Sangat Setuju (SS) & 4 \\
\hline Setuju (S) & 3 \\
\hline Tidak Setuju (TS) & 2 \\
\hline $\begin{array}{c}\text { Sangat Tidak Setuju } \\
\text { (STS) }\end{array}$ & 1 \\
\hline
\end{tabular}

Sumber : Sugiyono (2011:94)

Selanjutnya dicari rata-rata tiap jawaban responden. Untuk memudahkan penilaian dari rata-rata tersebut maka dibuatlah interval. Dalam penelitian ini penulis untuk menentukan banyaknya kelas interval adalah 4. Rumus yang digunakan sebegai berikut :

Panjang kelas interval $=$ Banyak rentang

interval

Dimana :

Rentang = nilai tertinggi - nialai terendah Berdasarkan rumus diatas maka panjang kelas interval adalah :

Panjang kelas interval $=\frac{4-1}{4}=0,75$

Maka interval dari penilaian adalah sebagai berikut :
1,00 - 1, 74 = Sangat Tidak Baik
$1,75-2,49=$ Tidak Baik
$2,50-3,24=$ Baik
$3,25-4,00=$ Sangat Baik

\section{HASIL DAN PEMBAHASAN}

Dari hasil pengumpulan data yang berkaitan dengan efektivitas kinerja karyawan terhadap penggunaan sistem E-Dosir, Maka dapat disimpulkan berikut :

Tabel 2. Hasil Kuisioner

\begin{tabular}{|l|c|c|c|c|c|}
\hline \multicolumn{1}{|c|}{ Pertanyaan } & $\begin{array}{c}\text { Sangat } \\
\text { Setuju (4) }\end{array}$ & $\begin{array}{c}\text { Setuju } \\
(3)\end{array}$ & $\begin{array}{c}\text { Tidak } \\
\text { Setuju (2) }\end{array}$ & $\begin{array}{c}\text { Sangat } \\
\text { Tidak } \\
\text { Setuju (1) }\end{array}$ & $\begin{array}{c}\text { Nilai Total } \\
\text { Rata-rata }\end{array}$ \\
\hline $\begin{array}{l}\text { Saat menggunakan e-Dosir, saya dapat } \\
\text { mengoperasikannya sesuai dengan } \\
\text { kebutuhan saya }\end{array}$ & 3 & 6 & 0 & 30 \\
\hline $\begin{array}{l}\text { Saya merasa e-Dosir sangat fleksibel untuk } \\
\text { digunakan }\end{array}$ & 4 & 4 & 1 & 0 & 30 \\
\hline $\begin{array}{l}\text { Interaksi saya dengan e-Dosir jelas dan } \\
\text { mudah dipahami }\end{array}$ & 6 & 3 & 0 & 0 & 3,33 \\
\hline $\begin{array}{l}\text { Saya jarang mengalami kebingungan saat } \\
\text { menggunakan e-Dosir }\end{array}$ & 5 & 3 & 1 & 0 & 3,67 \\
\hline $\begin{array}{l}\text { Tampilan e-Dosir mudah untuk dibaca } \\
\text { sehingga saya mudah untuk memahaminya }\end{array}$ & 7 & 2 & 0 & 3,44 \\
\hline Mudah bagi saya untuk mempelajari & 4 & 5 & 0 & 0 & 34 \\
\hline
\end{tabular}




\begin{tabular}{|l|c|c|c|c|c|c|}
\hline bagaimana cara menggunakan e-Dosir & & & & & \\
\hline $\begin{array}{l}\text { Saya tidak merasa e-Dosir merupakan } \\
\text { suatu sistem yang rumit }\end{array}$ & 3 & 5 & 1 & 0 & 29 & 3,22 \\
\hline $\begin{array}{l}\text { Saya dapat memperoleh informasi yang } \\
\text { saya butuhkan saat menggunakan e-Dosir }\end{array}$ & 6 & 2 & 1 & 0 & 32 & 3,56 \\
\hline $\begin{array}{l}\text { e-Dosir dapat memberi saya informasi } \\
\text { sesuai format yang dibutuhkan }\end{array}$ & 5 & 4 & 0 & 0 & 32 & 3,56 \\
\hline $\begin{array}{l}\text { Saya dapat memperoleh informasi yang } \\
\text { saya butuhkan saat menggunakan e-Dosir }\end{array}$ & 4 & 5 & 0 & 0 & 31 & 3,44 \\
\hline $\begin{array}{l}\text { Menggunakan e-Dosir memungkinkan saya } \\
\text { untuk mengerjakan tugas-tugas saya } \\
\text { dengan lebih cepat }\end{array}$ & 7 & 2 & 0 & 0 & 34 & 3,78 \\
\hline $\begin{array}{l}\text { e-Dosir memungkinkan saya untuk } \\
\text { mengerjakan tugas saya dengan lebih } \\
\text { praktis dan efisien }\end{array}$ & 4 & 4 & 1 & 0 & 30 & 3,33 \\
\hline $\begin{array}{l}\text { Menggunakan e-Dosir mempermudah } \\
\text { pekerjaan saya }\end{array}$ & 4 & 5 & 0 & 0 & 31 & 3,44 \\
\hline $\begin{array}{l}\text { Menggunakan e-Dosir mampu menambah } \\
\text { tingkat produktifitas saya }\end{array}$ & 4 & 4 & 1 & 0 & 30 & 3,33 \\
\hline $\begin{array}{l}\text { Saya tidak melakukan kesalahan- } \\
\text { kesalahan berlanjut ketika mengoperasikan } \\
\text { e-Dosir }\end{array}$ & 3 & 5 & 1 & 0 & 29 & 3,22 \\
\hline $\begin{array}{l}\text { Saya merasa puas dengan pelayanan } \\
\text { sistem e-Dosir }\end{array}$ & 6 & 3 & 0 & 0 & 33 & 3,67 \\
\hline Total & & & & & 300 & 55,33 \\
\hline
\end{tabular}

Jadi dapat dilihat dari tabel 4.1 bahwa tanggapan responden terhadap penggunaan sistem E-Dosir terhadap efektifitas kinerja karyawan pada umumnya dapat dikatakan sangat efektif karena nilai rata-rata dari keseluruhan pertanyaan adalah sebesar 3,70 dan berada di interval 3,25 - 4,00. Dengan hasil tersebut dapat ditarik kesimpulan bahwa dalam penggunaan sistem E-dosir dapat meningkatkan efektivitas kerja karyawan pada PT.Asabri Pontianak.

\section{E. KESIMPULAN}

Arsip merupakan sekumpulan berkas berisi informasi yang disimpan sebagai bahan pengingat dalam bentuk lembaran catatan maupun bentuk lain sedangkan arsip elektronik adalah suatu sistem kearsipan yang menggunakan sarana pengolahan data elektronik.

Konsep tingkat efektivitas kerja menunjuk pada tingkat sejauh mana pegawai melaksanakan kegiatan atau fungsi-fungsi sehingga tujuan yang telah ditetapkan dapat tercapai dengan menggunakan secara optimal alat-alat dan sumber-sumber yang ada, ketepatan waktu dalam melaksanakan tugas serta kemampuan untuk melaksanakan tugas tersebut yang dapat dilihat dari kualitas maupun kuantitas dan dapat bermanfaat bagi lingkungan kerjanya.

Berdasarkan hasil penelitian dan pembahasan yang telah di uraikan, maka dapat diperoleh kesimpulan bahwa di PT.Asabri (Persero) Pontianak terlihat berjalan efektf, dimana setiap kebutuhan pegawai bisa terpenuhi dengan baik. Hasil penelitian tersebut bahwa efektivitas kerja pegawai dalam penggunaan sistem elektronik dosir yang ada di PT. Asabri Pontianak saat ini sudah berjalan dengan efektif. terlihat bahwa presentase rata-rata jawaban responden yang berkaitan dengan efektivitas kerja karyawan dalam penggunaan sistem elektronik dosir adalah sebesar 3,70 yang berarti responden menyatakan efektivitas kerja penggunaan sistem kearsipan elektronik di PT.Asabri Pontianak tergolong sangat tinggi/sangat baik.

Dalam penggunaan sistem elektronik dosir yang ada di PT.Asabri Pontianak dalam penggunaan sistem elektronik ini memberikan kemudahan dalam proses pencarian atau temu balik arsip, memberikan kemudahan dalam pengelolaan dan penyimpanan data dan dokumen, dapat mengurangi biaya untuk perawatan dan penyimpanan karena arsip sudah di digitalisasikan atau disimpan dalam bentuk digital serta membantu pekerjaan emnjadi cepat dan efektif sehingga dapat meningkatkan pelayanan prima.

\section{DAFTAR PUSTAKA}

[1] Gie, The Liang (2000). Administrasi Perkantoran Modern. Yogyakarta, Super Sukses dan Nur Cahaya

[2] Haryadi, Hendi (2009). Administrasi Perkantoran Untuk Manajer Dan Staf. Jakarta: Visimedia.

[3] Kuswantoro, Agung dan Ahmad, Saeroji (2014). Manajemen Arsip Elektronik ( $E$ Arsip), Konsep dan Aplikasi dengan 
Microsoft Accsess. Semarang: Fastindo Make U Easy

[4] Mulyono, Sularso dkk (2011). Manajemen Kearsipan. Semarang: Unnes Press

[5] Odgers, P (2005). Administrative office management: Short course (13thed.). Mason, Ohio: Thomson South-Western

[6] Read, J. \& Ginn, M. L. (2011). Record management (9 thed.). Mason, Ohio: Thomson South-Western

[7] Sukoco, Badri Munir. 2007. Manajemen Administrasi Perkantoran Modern. Yogyakarta: Erlangga

[8] Sugiarto, Agus; Wahyono, Teguh (2005). Manajemen Kearsipan Modern dari Ke Basis Komputer. Jogjakarta: Gava Media

[9] Sugiyono (2011). Metode Penelitian Kuantitatif Kualitatif Dan $R$ \& $D$. Bandung. CV Alfabeta.

[10] Sedarmayanti (2005). Tata Kearsipan Dengan Memanfaatkan Teknologi Modern, Bandung: Mandar Maju.

[11] Wahyono, Teguh dan Sugiarto, Agus (2005). Manajemen Kearsipan Modern. Yogyakarta: Gava Media

[12] Undang-undang No.43 Tahun 2013. Tentang Kearsipan. Diambil dari https://www.kemhan.go.id/itjen/2014/06/2 5/peraturan-menteri-pertahananrepublikindonesia-nomor-43-tahun-20132013-tentang-pengurusan-dosir-pegawainegeri-sipil-dan-tentaranasionalindonesia-di-lingkungan-kementerianpertahanan.html 